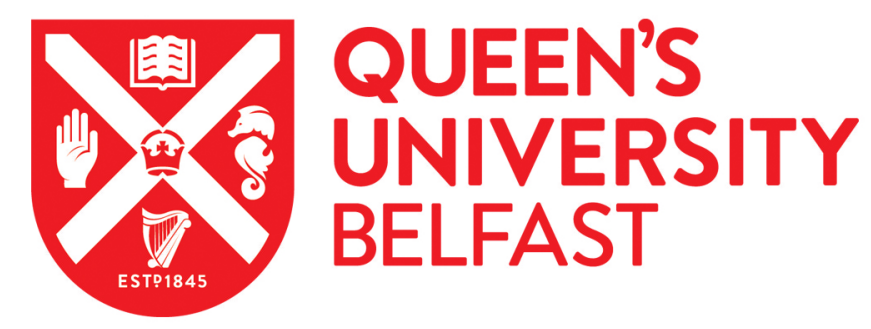

\title{
Reproductive factors, exogenous hormone use and bladder cancer risk in a prospective study
}

Cantwell, M., Lacey Jr, J. V., Schairer, C., Schatzkin, A., \& Michaud, D. S. (2006). Reproductive factors, exogenous hormone use and bladder cancer risk in a prospective study. International Journal of Cancer, 119 (10)(10), 2398-2401. https://doi.org/10.1002/ijc.22175

Published in:

International Journal of Cancer

Queen's University Belfast - Research Portal:

Link to publication record in Queen's University Belfast Research Portal

\section{General rights}

Copyright for the publications made accessible via the Queen's University Belfast Research Portal is retained by the author(s) and / or other copyright owners and it is a condition of accessing these publications that users recognise and abide by the legal requirements associated with these rights.

Take down policy

The Research Portal is Queen's institutional repository that provides access to Queen's research output. Every effort has been made to ensure that content in the Research Portal does not infringe any person's rights, or applicable UK laws. If you discover content in the Research Portal that you believe breaches copyright or violates any law, please contact openaccess@qub.ac.uk. 


\title{
Reproductive factors, exogenous hormone use and bladder cancer risk in a prospective study
}

\author{
Marie M. Cantwell ${ }^{1,2 *}$, James V. Lacey Jr. ${ }^{3}$, Catherine Schairer ${ }^{4}$, Arthur Schatzkin ${ }^{1}$ and Dominique S. Michaud ${ }^{1}$ \\ ${ }^{1}$ Nutritional Epidemiology Branch, Division of Cancer Epidemiology and Genetics, National Cancer Institute, \\ National Institutes of Health, Bethesda, MD \\ ${ }^{2}$ Cancer Prevention Fellowship Program, National Cancer Institute, National Institutes of Health, Bethesda, MD \\ ${ }^{3}$ Hormonal and Reproductive Epidemiology Branch, Division of Cancer Epidemiology and Genetics, \\ National Cancer Institute, National Institutes of Health, Bethesda, MD \\ ${ }^{4}$ Biostatistics Branch, Division of Cancer Epidemiology and Genetics, National Cancer Institute, \\ National Institutes of Health, Bethesda, MD
}

Sex is a consistent predictor of bladder cancer: men experience 24-fold higher age-adjusted rates than women in the U.S. and Europe. The objective of this study was to examine whether hormone-related factors are associated with bladder cancer in women. We examined parity, age at menarche, age at first birth, age at menopause, oral contraceptive use and menopausal hormone therapy (HT) use and bladder cancer risk in the Breast Cancer Detection Demonstration Project Follow-Up Study. Endpoint and exposure information was collected on 54,308 women, using annual telephone interviews (1980-86) and 3 mailed, self-administered questionnaires (1987-98). During an average follow-up time of 15.3 years, 167 cases of bladder cancer were identified. Univariate and adjusted rate ratios (RRs) were estimated using Poisson regression. Parity, age at menarche, age at first birth, age at menopause, and oral contraceptive use were not associated with bladder cancer risk. The majority of menopausal women who took HT used estrogen therapy (ET). Postmenopausal women with less than 4 years, 4-9 years, 10-19 years and 20 or more years of ET use had RRs of $1.55(95 \% \mathrm{CI}=\mathbf{0 . 9 6}-2.51), 1.00(95 \% \mathrm{CI}=\mathbf{0 . 4 9}$ 2.04), $1.23(95 \% \mathrm{CI}=0.62-2.43)$ and $0.57(95 \% \mathrm{CI}=\mathbf{0 . 1 4 - 2 . 3 4})$, respectively, compared with nonusers $(p=0.50)$. Findings from this study are not consistent with the hypothesis that hormonerelated factors in women are associated with bladder cancer.

(C) 2006 Wiley-Liss, Inc.

Key words: bladder cancer; hormone therapy; reproductive factors; estrogen; parity; age at menarche; menopause

In 2001, the U.S. age-adjusted incidence rates (per 100,000 persons) for bladder cancer were 37.1 in men and 9.4 in women. ${ }^{1} \mathrm{Sex}$ is a consistent predictor of bladder cancer: men experience 2-4fold higher rates than women in the U.S. and Europe. ${ }^{2,3}$ Greater exposure to established environmental risk factors, such as industrial exposures ${ }^{4}$ and cigarette smoking, ${ }^{5}$ in men explains some, but not all, of the higher risk. ${ }^{6}$ The reduced risk in women may be explained in part by hormones or correlates of hormonal status, such as age at menarche, parity or age at menopause. ${ }^{6}$

Evidence from animal studies suggests that sex hormones play an important role in bladder cancer etiology, ${ }^{7,8}$ but few human studies have addressed the potential association between reproductive factors and bladder cancer. ${ }^{9}$ Three population-based ecologic studies ${ }^{10-12}$ reported lower bladder cancer incidence or mortality rates among parous women than nulliparous women. Case-control studies reported reduced risks in parous women, which were stronger among never-smokers, and increased risks in menopausal hormone therapy users. ${ }^{13,14}$ Recent findings suggest that menopausal status and age at menopause may play a role in modifying bladder cancer risk among women. ${ }^{15}$ Postmenopausal women, compared with premenopausal women, were at increased risk (incidence rate ratio $=1.93,95 \% \mathrm{CI}$ 0.99-3.78). For postmenopausal women, early menopause $(\leq 45$ years), compared with late menopause ( $\geq 50$ years), was associated with a statistically significant increased risk of bladder cancer (incidence rate ratio $=1.63,95 \%$ CI $1.20-2.23$ ).

Outside the hypothesized environmental risk factor differences, the reason for lower bladder cancer incidence rates in women compared with that in men remains largely unexplained. We therefore examined reproductive factors, oral contraceptive use and postmenopausal hormone use, and risk of bladder cancer in the Breast Cancer Detection and Demonstration Project (BCDDP) Follow-up Study.

\section{Material and methods \\ Study population}

In 1979, the National Cancer Institute (NCI) established a follow-up study of 64,182 of the 283,222 original BCDDP participants. The study included women from all 29 screening centers in 27 cities $^{16}$ and consisted of 4,275 women from the BCDDP who were diagnosed with breast cancer, 25,114 women who had breast surgery with no evidence of malignant disease, 9,628 women who were recommended for surgical consultation during the screening, and a sample of women who had neither surgery nor recommendation for surgical consultation $(n=25,165) .{ }^{7}$ Institutional Review Boards at the NCI and participating clinics approved the study. All participants provided informed consent.

\section{Cohort follow-up}

Data collection occurred in 4 phases. 61,430 (96\%) of the invited cohort agreed to participate and completed a baseline interview, Phase 1 (1980-1986), which included up to 6 (usually 4) annual telephone interviews. During Phases 2 (1987-1989), 3 (1993-1995) and 4 (1995-1998), participants were mailed single, self-administered questionnaires. Nonrespondents to the mailed questionnaires were interviewed by telephone, if possible.

\section{Exposure ascertainment}

Demographic (e.g. education, ethnicity and income) and reproductive (e.g., age at menarche, age at first live birth, menopausal status and parity) data were collected during Phase 1. Menopausal status and gynecologic surgery data were queried at each phase. Height and weight were measured during the original screening project (1973-1979). Oral contraceptive data, including duration of and age at first use of birth control pills, was collected at Phase

The views expressed in this manuscript are solely those of the authors, and do not necessarily reflect the opinions of any state agency listed in the Acknowledgements.

Dominique S. Michaud's current address is: Department of Epidemiology, Harvard School of Public Health, Boston, MA.

Grant sponsor: National Cancer Institute.

*Correspondence to: Cancer Epidemiology and Prevention Research, Centre for Clinical and Population Sciences, Queen's University Belfast, Mulhouse Building, Royal Group of Hospitals, Grosvenor Road, Belfast BT12 6BJ, UK. Fax: +44-2890-231907. E-mail: m.cantwell@qub.ac.uk

Received 12 October 2005; Accepted after revision 3 May 2006

DOI 10.1002/ijc.22175

Published online 7 August 2006 in Wiley InterScience (www.interscience. wiley.com). 
1 only. Menopausal hormone therapy (HT) use, including formulation, ages at first and last use, and duration, was collected at each phase, as previously described. ${ }^{16,17}$ Smoking status and history, including years smoked, smoking intensity, and ages started and stopped, were obtained on the Phase 2 questionnaire and updated during Phase 3.

\section{Cancer ascertainment}

Each questionnaire asked participants about cancer diagnoses since their last interview. We verified reported bladder cancer diagnoses [ICD codes 188.x (ICDO-1) and C67.x (ICDO-2)] through medical record review. The cohort was linked against the National Death Index (NDI) to identify deaths and cause of death during follow-up. In 1999-00, we also linked 44,139 women ( $72 \%$ of baseline interview respondents; $85 \%$ of Phase 2 respondents) to available state cancer registries, using the state of participants' last-known address, to identify additional cancer diagnoses. We identified 167 bladder cancers: 105 were confirmed via pathology reports or medical records, 29 via linkage with state cancer registries, and 25 via linkage with the NDI; 18 were based only on self-report. When medical records were available for review, $99 \%$ of self-reported cancers were confirmed. Nineteen of the 29 registry-based bladder cancers were not reported by study participants. If we assume a similar level of false-negative reporting among the 15,501 women in this analysis who were not linked to state cancer registries, then we estimate our combined ascertainment methods identified $95 \%$ of all incident bladder cancers in this study population during the study period.

\section{Analytic data set}

After excluding women with a missing date of death $(N=5)$, reported a diagnosis of bladder cancer $(N=43)$ or another primary cancer $(N=7,070)$ before baseline (including breast cancers identified during the BCDDP), or reported a bladder cancer diagnosis with an undetermined date $(N=4)$, the analysis included 54,308 women. The numbers of women who subsequently completed Phases 2, 3 and 4 questionnaires were 45,863 (84\%), 40,052 (74\%) and 38,147 $(70 \%)$, respectively. Death, $(N=1,336,2.5 \%)$, refusal $(N=2,007$, $3.7 \%$ ), illness or inability to contact the woman before the end of the questionnaire period $(N=1,953,3.6 \%)$ and incomplete questionnaires $(N=3,149,5.8 \%)$ accounted for missing Phase 2 questionnaires. Respective numbers for missing Phase 3 and Phase 4 questionnaires were $4,535(8.4 \%), 555(2.9 \%) 1,077(2.0 \%)$ and 7,089 (13.1\%); and 6,886 (12.7\%), 2,406 (4.4\%), 3,045 (5.6\%) and 824 $(7.0 \%)$. At the end of follow-up, endpoint status was known for $86.9 \%$ of the 54,308 women: $72.7 \%$ were censored at the Phase 4 interview or date of last contact; $13.8 \%$ had died; and $0.3 \%$ had been diagnosed with bladder cancer. The $13.2 \%$ of the cohort for whom we assigned a censoring date had all completed at least some follow-up data $(11.9 \%$ through Phase 3, 1.1\% through Phase 2 and $0.3 \%$ through Phase 1 ).

\section{Statistical analysis}

Person-time was computed for each participant from her baseline interview date until the date of a bladder cancer diagnosis, death or completion of a Phase 4 questionnaire, whichever came first. ${ }^{18}$ For women who did not respond to the Phase 4 questionnaire, person-time was computed until the date of last contact (e.g., a notice of refusal to participate) or the estimated date they would have completed the Phase 4 questionnaire. Based on the NDI and cancer registry linkages, we assumed that women without a Phase 4 questionnaire were alive and disease-free. ${ }^{19}$

Time-dependent covariates for age, calendar time, menopausal status, smoking and HT use were updated at 1-year intervals. To analyze smoking and HT use in a time-dependent manner, periods of use were reconstructed using reported dates of exposure.

Poisson regression modeled the rate of developing bladder cancer during follow-up and generated rate ratios (RRs) with $95 \%$ confidence intervals (CIs) for categorized variables, using standard likelihood ratio methods ${ }^{20}$ in EPICURE software. ${ }^{21}$ Potential confounding was assessed by evaluating parameter estimate changes before and after the addition of variables associated with both exposures and bladder cancer. Adjusted and unadjusted RRs were generally similar. We present the adjusted models, which included stratification on age (5-year intervals), calendar time (5-year intervals) and smoking status (current, former, never smoker). Because smoking is a strong bladder cancer risk factor, we also considered smoking duration, but adjustment for both status and duration ${ }^{22}$ did not change the results. We therefore present the more parsimonious models based on smoking status only.

\section{Results}

The cohort accrued 338,502 person-years of follow-up. The mean \pm SD ages (in years) at entry and exit were $55.4 \pm 8.8$ and $70.6 \pm 8.4$, respectively. The mean \pm SD follow-up times were $15.3 \pm 2.8$ years and $9.8 \pm 4.2$ years for censored women and women who developed bladder cancer, respectively. Table I shows descriptive characteristics of the analytic population.

There was no association between bladder cancer and age at menarche or age at first birth (Table II). Parous women had a statistically nonsignificant reduced risk compared with nulliparous women (RR 0.82; 95\% CI 0.56-1.20), but we observed no trend with increasing parity. The null association with parity did not change after stratification by smoking status (data not shown). Compared with natural menopause at 50-53 years, both earlier

TABLE I - DESCRIPTIVE CHARACTERISTICS OF THE WOMEN IN THE

\begin{tabular}{|c|c|c|c|c|}
\hline & Cancers & Person-years & $\mathrm{RR}^{1}$ & $95 \% \mathrm{CI}$ \\
\hline \multicolumn{5}{|l|}{$\operatorname{Age}^{2}$ (years) } \\
\hline$<50$ & 2 & 28,609 & 1.00 & ref \\
\hline $50-54$ & 9 & 51,324 & 1.93 & $0.42-9.01$ \\
\hline $55-59$ & 27 & 69,447 & 3.86 & $0.90-16.48$ \\
\hline $60-64$ & 28 & 67,802 & 3.89 & $0.90-16.65$ \\
\hline $65-69$ & 25 & 54,531 & 4.21 & $0.97-18.20$ \\
\hline $70-74$ & 31 & 37,025 & 7.68 & $1.79-32.93$ \\
\hline$>75$ & 45 & 29,763 & 13.61 & $3.21-57.78$ \\
\hline \multicolumn{5}{|l|}{ Race } \\
\hline Caucasian American & 153 & 287,859 & 1.00 & ref \\
\hline African-American & 4 & 16,704 & 0.46 & $0.17-1.25$ \\
\hline Hispanic-American & 4 & 10,009 & 0.77 & $0.29-2.09$ \\
\hline Asian-American & 3 & 15,142 & 0.42 & $0.13-1.33$ \\
\hline Other & 3 & 8,789 & 0.71 & $0.23-2.24$ \\
\hline \multicolumn{5}{|l|}{ Education } \\
\hline$<$ High School & 30 & 43,726 & 1.00 & ref \\
\hline High School & 62 & 141,649 & 0.83 & $0.53-1.30$ \\
\hline$>$ High School & 74 & 150296 & 0.92 & $0.60-1.43$ \\
\hline Unknown & 1 & 2830 & 0.66 & $0.09-4.87$ \\
\hline \multicolumn{5}{|l|}{ Body mass index $\left(\mathrm{kg} / \mathrm{m}^{2}\right)$} \\
\hline$<18.5$ & 2 & 7,469 & 0.55 & $0.14-2.24$ \\
\hline 18.5 to $<25$ & 103 & 214,102 & 1.00 & ref \\
\hline 25 to $<30$ & 42 & 78,414 & 1.05 & $0.73-1.50$ \\
\hline 30 to $<35$ & 14 & 22,348 & 1.28 & $0.73-2.25$ \\
\hline$\geq 35$ & 3 & 8,142 & 0.83 & $0.26-2.63$ \\
\hline Unknown & 3 & 8,026 & 0.79 & $0.25-2.50$ \\
\hline \multicolumn{5}{|l|}{ Smoking status ${ }^{2}$} \\
\hline Never smoker & 62 & 172,600 & 1.00 & ref \\
\hline Current smoker & 30 & 48,780 & 2.44 & $1.56-3.80$ \\
\hline Former smoker & 50 & 80719 & 1.69 & $1.16-2.46$ \\
\hline Unknown & 25 & 36402 & 1.81 & $1.13-2.89$ \\
\hline \multicolumn{5}{|l|}{ Smoking duration $^{2}$ (years) } \\
\hline Never smoker & 62 & 172,600 & 1.0 & ref \\
\hline$<20$ & 8 & 36,915 & 0.73 & $0.35-1.53$ \\
\hline $20-39$ & 38 & 67,371 & 1.95 & $1.29-2.93$ \\
\hline$>40$ & 34 & 26,758 & 2.75 & $1.80-4.20$ \\
\hline Unknown & 25 & 34,858 & 1.89 & $1.18-3.02$ \\
\hline
\end{tabular}

${ }^{1}$ Adjusted for age, calendar year and smoking status (never, former or current) except for age RRs (adjusted for calendar year and smoking) and Smoking RRs (adjusted for age and calendar year). $-{ }^{2}$ Time dependent variables. 
TABLE II - REPRODUCTIVE FACTORS AND BLADDER CANCER RISK IN THE BCDDP

\begin{tabular}{|c|c|c|c|c|}
\hline & Cancers & Person-years & $\mathrm{RR}^{1}$ & $95 \% \mathrm{CI}$ \\
\hline \multicolumn{5}{|c|}{ Age of menarche (years) } \\
\hline$<12$ & 25 & 58,895 & 1.00 & ref \\
\hline 12 & 46 & 85,647 & 1.19 & $0.73-1.93$ \\
\hline 13 & 51 & 101265 & 1.10 & $0.68-1.78$ \\
\hline 14 & 22 & 50,112 & 0.89 & $0.50-1.58$ \\
\hline$>14$ & 23 & 40,479 & 1.12 & $0.63-1.98$ \\
\hline \multicolumn{5}{|c|}{ Age at first birth (years) } \\
\hline Nulliparous & 30 & 44,961 & 1.00 & ref \\
\hline$\leq 20$ & 43 & 72,840 & 1.13 & $0.70-1.81$ \\
\hline $21-25$ & 54 & 136,212 & 0.73 & $0.47-1.15$ \\
\hline $26-30$ & 28 & 62454 & 0.73 & $0.43-1.22$ \\
\hline$>30$ & 12 & 21,578 & 0.78 & $0.40-1.52$ \\
\hline \multicolumn{5}{|l|}{ Parity } \\
\hline Nulliparous & 30 & 44,961 & 1.00 & ref \\
\hline $1+1$ & 17 & 39927 & 0.65 & $0.36-1.18$ \\
\hline 2 & 55 & 98,786 & 0.96 & $0.61-1.50$ \\
\hline 3 & 35 & 79,838 & 0.82 & $0.50-1.34$ \\
\hline$>4$ & 30 & 74,828 & 0.75 & $0.45-1.25$ \\
\hline \multicolumn{5}{|c|}{ Menopausal status/type } \\
\hline Natural & 103 & 168,220 & 1.00 & ref \\
\hline Surgical & 32 & 56,501 & 1.04 & $0.70-1.55$ \\
\hline Unknown Status & 28 & 90,084 & 0.64 & $0.42-0.97$ \\
\hline Other type & 3 & 1,949 & 2.20 & $0.70-6.96$ \\
\hline Premenopausal & 1 & 21,693 & 0.27 & $0.03-2.07$ \\
\hline \multicolumn{5}{|c|}{ Age at natural menopausal (years) } \\
\hline$<45$ & 15 & 16,200 & 1.53 & $0.82-2.82$ \\
\hline $45-49$ & 32 & 57,784 & 1.06 & $0.65-1.71$ \\
\hline $50-53$ & 36 & 71,182 & 1.00 & ref \\
\hline$\geq 54$ & 20 & 23,024 & 1.59 & $0.92-2.77$ \\
\hline
\end{tabular}

Unknown age at menarche accounted for 2,104 person-years. Unknown parity accounted for 162 person-years. Unknown age at first birth accounted for 458 person-years. Unknown menopausal status accounted for 55 person-years. Unknown age at natural menopause accounted for 30 person-years.

${ }^{1}$ Adjusted for age, calendar year and smoking status (never, former or current). Further adjustment for combined smoking status and duration did not change the results (see Material and Methods).

( $\leq 45$ years) and later ( $\geq 54$ years) natural menopause were positively but not significantly associated with bladder cancer. The test for trend was not statistically significant.

There was no association between OC use and bladder cancer, although women who used OCs for more than 5 years had a statistically nonsignificant decreased risk (RR 0.59; 95\% CI 0.25-1.37) compared with nonusers (Table III). Among postmenopausal women, we observed no association between ever-use of HT formulations and bladder cancer. The majority of use was unopposed estrogen therapy (ET), but no statistically significant association with increasing duration of use emerged.

Current, former, and longer duration of smoking were all positively associated with bladder cancer. Women who smoked for 40 years or more had a RR of $2.44(95 \%$ CI $=1.56-3.80)$ compared with never-smokers ( $p$-value for categorical smoking duration: $<0.0002)$. To further evaluate potential residual confounding by smoking, we calculated RRs that were simultaneously stratified by smoking status and adjusted for smoking duration. Early menopause has been positively associated with smoking, but the RR for natural menopause before age 45 , compared with menopause at 50-53 years, did not materially change after also adjusting for smoking duration [natural menopause $<45$ years: RR $(95 \% \mathrm{CI})$ in never smokers ( $N=5$ cancers $), 1.87(0.89-3.91)$; RR $(95 \% \mathrm{CI})$ in former smokers $(N=6$ cancers $), 1.50(0.74-3.08)$; RR $(95 \% \mathrm{CI})$ in current smokers $(N=2$ cancers $), 0.71(0.28-1.81)], 2$ women had unknown smoking status. No other results materially differed.

\section{Discussion}

This prospective study of 54,308 women who were followed for almost 20 years produced no associations between reproductive
TABLE III - ORAL CONTRACEPTIVE AND HORMONE THERAPY USE AND BLADDER CANCER RISK IN THE BCDDP FOLLOW-UP STUDY

\begin{tabular}{|c|c|c|c|c|}
\hline & Cancers & Person-years & $\mathrm{RR}^{1}$ & $95 \% \mathrm{CI}$ \\
\hline \multicolumn{5}{|l|}{ Oral contraceptive use } \\
\hline $\begin{array}{l}\text { Never used oral } \\
\text { contraceptives }\end{array}$ & 125 & 231,728 & 1.00 & ref \\
\hline $\begin{array}{l}\text { Ever used oral } \\
\text { contraceptives }\end{array}$ & 41 & 105,484 & 1.14 & $0.77-1.70$ \\
\hline \multicolumn{5}{|c|}{ Duration of use (years) } \\
\hline$<2$ & 21 & 48,303 & 1.25 & $0.76-2.04$ \\
\hline $2-5$ & 14 & 26,652 & 1.56 & $0.87-2.78$ \\
\hline$>5$ & 6 & 30,529 & 0.59 & $0.25-1.37$ \\
\hline \multicolumn{5}{|l|}{$\mathrm{HT}_{\mathrm{use}}^{2}$} \\
\hline Never used HT & 53 & 90396 & 1.00 & ref \\
\hline Ever used HT & 74 & 126,153 & 0.98 & $0.71-1.37$ \\
\hline \multicolumn{5}{|l|}{ HT Formulation } \\
\hline ET only & 51 & 75,840 & 1.15 & $0.81-1.63$ \\
\hline EPT & 14 & 35,324 & 0.60 & $0.33-1.07$ \\
\hline ET/unknown PT & 9 & 14,989 & 0.81 & $0.40-1.64$ \\
\hline Unknown HT & 11 & 101,212 & 1.44 & $0.75-2.74$ \\
\hline \multicolumn{5}{|c|}{ Duration of ET use (years) ${ }^{3}$} \\
\hline Never used ET & 53 & 90,396 & 1.00 & ref \\
\hline$<4$ & 25 & 30,052 & 1.55 & $0.96-2.51$ \\
\hline $4-9$ & 9 & 17,829 & 1.00 & $0.49-2.04$ \\
\hline $10-19$ & 10 & 14,632 & 1.23 & $0.62-2.43$ \\
\hline$\geq 20$ & 2 & 4,553 & 0.57 & $0.14-2.34$ \\
\hline
\end{tabular}

HT, menopausal hormone therapy; ET, estrogen therapy; EPT, estrogen and progestin therapy; ET/unknown PT, estrogen therapy with unknown progestin therapy. Unknown oral contraceptive use accounted for 1 cancer and 1,551 person-years; RR $=1.80(95 \% \mathrm{CI}$ $0.25-12.94)$. Unknown duration of estrogen therapy use accounted for 5 cancers and 10410 person-years; RR $=0.78$ (95\% CI, 0.31-1.97).

${ }^{1}$ Adjusted for age, calendar year and smoking status (never, former or current). Further adjustment for combined smoking status and duration did not change the results (see Material and Methods). $-{ }^{2}$ Among post menopausal women only.- ${ }^{3}$ Among post menopausal women who used ET only; excludes women whose duration of use was unknown.

factors, exogenous hormones, and bladder cancer. Early reproductive events, such as age at menarche, age at first birth and parity, were not associated with bladder cancer. Both older $(\geq 54$ years) and younger $(<45$ years) ages at natural menopause appeared to similarly increase risk, compared with menopause at 50-53 years, but only the former was statistically significant. Neither type nor duration of exogenous hormone use was associated with bladder cancer.

Previous studies offer inconsistent data on these potential associations. In an Italian case-control study that included 110 cases and 298 controls, Pelucchi et al. ${ }^{14}$ found no significant associations between bladder cancer and menstrual and reproductive factors, including parity and late age at first birth. An earlier case-control study by Cantor et al. ${ }^{13}$ in Iowa showed an inverse association with parity (adjusted OR $=0.67,95 \%$ CI $0.44-1.00$, for parous $v s$. nulliparous) that was restricted to women who had never smoked before $(\mathrm{OR}=0.51,95 \% \mathrm{CI}$ $0.30-0.88)$; parity was not associated with bladder cancer among ever-smokers $(\mathrm{OR}=0.93,95 \%$ CI $0.49-1.77)$. We did not replicate those findings.

More recently, McGrath et al. ${ }^{15}$ showed that for postmenopausal women, early menopause ( $\leq 45$ years), compared with late menopause ( $\geq 50$ years), was associated with a statistically significant increased risk of bladder cancer (incidence rate ratio $=1.63$, 95\% CI 1.20-2.23). We also showed an increased risk for women with an earlier menopause although this was not statistically significant $(\mathrm{RR}=1.53,95 \% \mathrm{CI} 0.82-2.82)$. There were however only 15 cases in this younger age category in our study compared with 71 in the study of McGrath et al.

Pelucchi et al. ${ }^{14}$ reported that both ever-use $(\mathrm{OR}=3.29,95 \%$ CI 1.49-7.25) and increasing duration of HT use were significantly associated with bladder cancer. They mentioned detection 
bias as a possible explanation for those associations, because postmenopausal bleeding in HT users may facilitate surveillance for other medical conditions. ${ }^{23}$ Persson et al. ${ }^{24}$ found no relationship with menopausal HT in a Swedish record-linkage study. The population-based cohort of Olsson et al. ${ }^{25}$ showed bladder cancer risk among smokers was decreased for those who ever used HT compared with that for those who did not. In our study, most of the associations with these potential risk factors were null, or could be due to chance.

The reported frequencies of exogenous hormone use generated $90 \%$ power (using a two-sided $\alpha=0.05$ ) to detect a RR of 0.50 for unopposed ET and $80 \%$ power to detect a RR of 0.50 for oral contraceptive use. Yet, even our relatively large cohort, which was followed for 20 years, had lower statistical power for other potential associations. We therefore cannot rule out smaller increased or decreased risks. Potential unmeasured confounding is another limitation: we lacked information on other hypothesized risk factors, such as urinary tract infections, ${ }^{26,27}$ micturition, ${ }^{28}$ hair dyes $^{29}$ or pesticides. ${ }^{30}$

There are several strengths to our study. We updated time-varying exposure information throughout follow-up and assessed exposures collected prior to bladder cancer diagnosis. Previous analysis of $\mathrm{HT}^{17,18}$ in BCDDP are consistent with the small increased relative risks noted in other studies, which argues against significant HT exposure misclassification. Other studies have shown that self-reported oral contraceptive use and recall of self-reported reproductive factors, such as ages at menarche and menopause, are reproducible and generally valid. $^{31,32}$ Finally, the significantly increased risks among smokers suggest good internal validity in our data.

In summary, our study does not support the hypothesis that differences in hormone-related factors in women are associated with bladder cancer risk. No specific factors other than smoking were associated with bladder cancer in our data. Further investigations into other potential explanations for the difference in bladder cancer risk between men and women are needed.

\section{Acknowledgements}

We thank the BCDDP participants; Ms. Susan Englehart, MS, Ms. Catherine Ann Grundmayer, BA, and the members of the BCDDP Staff at Westat Inc., Rockville, MD, and Ms. Leslie Carroll, BA, Mr. Franklin Demuth, BS, and Ms. Jennifer Boyd-Morin, BS, of IMS Inc., Silver Spring, MD, for computer support. We acknowledge the California Department of Health Services, Cancer Surveillance Section; Florida Cancer Data System, under contract to the Florida Department of Health; Maryland Cancer Registry, Maryland Department of Health and Mental Hygiene; Michigan Cancer Surveillance Program within the Division of Vital Records and Health Statistics, Michigan Department of Community Health; Pennsylvania Department of Health; Tennessee Cancer Registry; Texas Department of Health; and the states of Arizona, Georgia, Hawaii, Idaho, Iowa, New Jersey, New York, North Carolina, Ohio, Oregon and Rhode Island for providing data from their cancer registries for use in these analyses.

\section{References}

1. Surveillance, Epidemiology, and End Results (SEER) Program. SEER 1975-2001. Surveillance Research Program, Cancer Statistics Branch, National Cancer Institute, DCCPS, Bethesda, MD, 2004.

2. Thorn M, Bergstrom R, Johansson AM, Ramstrom L, Persson I, Malmstrom PU. Trends in urinary bladder cancer incidence in Sweden 1960-93 with special reference to histopathology, time period, birth cohort, and smoking. Cancer Causes Control 1997;8:560-7.

3. Hayne D, Arya M, Quinn MJ, Babb PJ, Beacock CJM, Patel HRH. Current trends in bladder cancer in England and Wales. J Urol 2004; 172:1051-5.

4. Colt JS, Baris D, Stewart P, Schned AR, Heaney JA, Mott LA, Silverman D, Karagas M. Occupation and bladder cancer risk in a population-based case-control study in New Hampshire. Cancer Causes Control 2004;15:759-69.

5. Castelao JE, Yuan JM, Skipper PL, Tannenbaum SR, Gago-Dominguez M, Crowder JS, Ross RK, Yu MC. Gender-and smoking related bladder cancer risks. J Natl Cancer Inst 2001;93:538-45.

6. Hartge P, Harvey EB, Linehan WM, Silverman DT, Sullivan JW, Hoover RN, Fraumeni JF, Jr. Unexplained excess risk of bladder cancer in men. J Natl Cancer Inst 1990;82:1636-40.

7. Terada S, Suzuki N, Uchide K, Akasofu K, Nishida E. Effect of testosterone on the development of bladder tumors and calculi in female rats. Gynecol Obstet Invest 1992;34:105-10.

8. Bertram JS, Craig AW. Specific induction of bladder cancer in mice by butyl-(4-hydroxybutyl)-nitrosamine and the effects of hormonal modifications on the sex difference in response. Eur J Cancer 1972;8: 587-94.

9. IARC Working Group. Hormonal contraception and post menopausal hormonal therapy.IARC monographs on the evaluation of carcinogenic risks to humans, vol. 72. IARC, Lyon, 1999. 1-492.

10. Miller AB, Barclay TH, Choi NM, Grace MG, Wall C, Plante M, Howe GR, Cinader B, Davis FG. A study of cancer, parity and age at first birth. J Chronic Dis 1980;33:595-605.

11. Plesko I, Preston-Martin S, Day NE, Tzonou A, Dimitrova E, Somogyi J. Parity and cancer risk in Slovakia. Int J Cancer 1985;36:529-33.

12. Green A, Beral V, Moser K. Mortality in women in relation to their childbearing history. BMJ 1988;297(6645):391-5.

13. Cantor KP, Lynch CF, Johnson D. Bladder cancer, parity, and age at first birth. Cancer Causes Control 1992;3:57-62.

14. Pelucchi C, La Vecchia C, Negri E, Dal Maso L, Franceschi S. Smoking and other risk factors for bladder cancer in women. Prev Med 2002;35:114-20.

15. McGrath M, Michaud DS, De Vivo I. Hormonal and reproductive factors and the risk of bladder cancer in women. Am J Epidemiol 2006; $163: 236-44$

16. Schairer C, Byrne C, Keyl PM, Brinton LA, Sturgeon SR, Hoover RN. Menopausal estrogen and estrogen-progestin replacement therapy and risk of breast cancer (United States). Cancer Causes Control 1994;5: 491-500.

17. Schairer C, Lubin J, Troisi R, Sturgeon S, Brinton L, Hoover RN. Menopausal estrogen and estrogen-progestin replacement therapy and breast cancer risk. JAMA 2000;283:485-91.

18. Lacey JV, Jr, Mink PJ, Lubin JH, Sherman ME, Troisi R, Hartge P, Schatzkin A, Schairer C. Menopausal hormone replacement therapy and risk of ovarian cancer. JAMA 2002;288:334-41.

19. Kato I, Toniolo P, Koenig KL, Kahn A, Schymura M, Zeleniuch-Jacquotte A. Comparison of active and cancer registry-based follow-up for breast cancer in a prospective cohort study. Am J Epidemiol 1999;149:372-8.

20. Breslow NE, Day NE. Statistical methods in cancer research. In: Breslow NE, Day NE, eds. The design and analysis of cohort studies, vol. 2. Lyon: IARC Scientific Publications, 1987, 1-406.

21. Preston DL, Lubin J, Pierce DA, McConney ME. EPICURE [software], release 2.0 edn. Seattle, WA: HiroSoft International, 1996

22. McKnight B, Cook LS, Weiss NS. Logistic regression analysis for more than one characteristic of exposure. Am J Epidemiol 1999;149: 984-92.

23. La Vecchia C, Brinton LA, McTiernan A. Menopause, hormone replacement therapy and cancer. Maturitas 2001;39:97-115.

24. Persson I, Yuen J, Bergkvist L, Schairer C. Cancer incidence and mortality in women receiving estrogen and estrogen-progestin replacement therapylong-term follow-up of a Swedish cohort. Int J Cancer 1996;67:327-32.

25. Olsson $\mathrm{H}$, Bladstrom A, Ingvar C. Are smoking-associated cancers prevented or postponed in women using hormone replacement therapy? Obstet Gynecol 2003;102:565-70.

26. Schairer C, Hartge P, Hoover RN, Silverman DT. Racial differences in bladder cancer risk: a case-control study. Am J Epidemiol 1988;128 $1027-37$

27. D’Avanzo B, La Vecchia C, Negri E, Decarli A, Benichou J. Attributable risks for bladder cancer in Northern Italy. Ann Epidemiol 2005; 5:427-31.

28. Mueller E, Latini J, Lux M, Stablein U, Brubaker L, Kreder K, Fitzgerald MP. Gender differences in 24-hour urinary diaries of asymptomatic North American adults. J Urol 2005;173:490-92.

29. Andrew A, Schned AR, Heaney JA, Karagas MR. Bladder cancer risk and personal hair dye use. Int J Cancer 2004;109:581-6.

30. Viel JF, Challier B. Bladder cancer among French farmers: does exposure to pesticides in vineyards play a part? Occup Environ Med 53: $587-92$.

31. Hunter DJ, Manson JE, Colditz GA, Chasan-Taber L, Troy L, Stampfer MJ, Speizer FE, Willett WC. Reproducibility of oral contraceptive histories and validity of hormone composition reported in a cohort of US women. Contraception 1997;56:373-8.

32. Bean JA, Leeper JD, Wallace RB, Sherman BM, Jagger H. Variations in the reporting of menstrual histories. Am J Epidemiol 1979;109: 181-5. 